
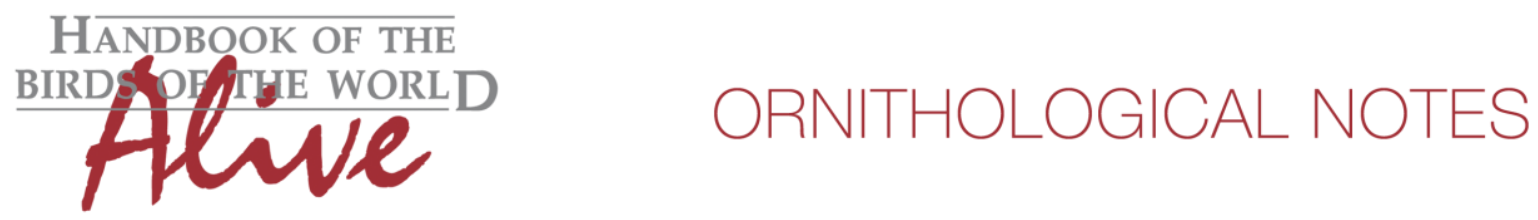

\title{
Notes on the vocalizations of Chestnut Antpitta (Grallaria blakei)
}

Peter Boesman

In the following we briefly analyze and compare voice of the different races of Chestnut Antpitta (Grallaria blakei). We also try to quantify the extent of any vocal differences using the criteria proposed by Tobias et al. (2010), as a support for taxonomic review. We have made use of sound recordings available on-line from Xeno Canto (XC).

There are clearly two vocal groups. Although Chestnut Antpitta is monotypic, it is thus likely that southern birds are a different undescribed taxon (this taxon was first discovered in Pasco, E of Oxapampa (Pasco) in the '80s and it was known for years as 'Pasco Antpitta sp.nov.', but in 2008 we found it in Junín further south (and documented not only song but also call for the first time), for which the English name 'Pasco Antpitta' nolonger is appropriate).

Song couldn't be more different (Fig. 1):

Song of northern birds ( $\mathrm{S}$ to Huanuco)

A soft monotonous fast series of notes (the first 1-2 notes slightly slower), given at intervals

$\begin{array}{ll}\text { \# of notes } & 17-35 \\ \text { total length } & 1.4-3.2 \mathrm{~s} \\ \text { note length } & 0.055-0.08 \mathrm{~s} \\ \text { max. frequency } & 1840-2065 \mathrm{~Hz}\end{array}$

\section{Song of southern birds (Pasco/Junin)}

A loud single note, repeated at intervals.

$\begin{array}{ll}\text { \# of notes } & 1 \\ \text { total length } & 0.18-0.2 \mathrm{~s} \\ \text { note length } & 0.18-0.2 \mathrm{~s} \\ \text { max. frequency } & 2350-2600 \mathrm{~Hz}\end{array}$

(Call is a slightly descending series of notes, even in case one would consider this to be the song, difference with northern birds is still considerable. I believe however this is the call as it is only given occasionally, just once naturally, or every time when triggered to vocalize)

Song and call of southern birds is not unlike southern races of $G$. rufula, but it is sympatric with $G$. rufula obscura, which together with elevational distribution (and morphology?) seems to confirm it is rather related to $G$. blakei.

When applying Tobias criteria, based on number of notes (score 3-4) and note length (3-4) or total song length (3-4), and max. frequency (score 2), this would lead to a total vocal score of about 7. 


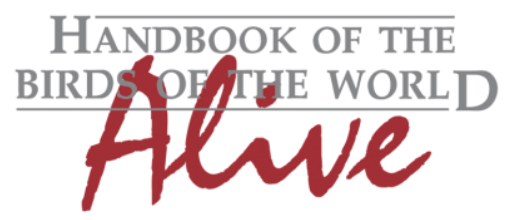

\section{ORNITHOLOGICAL NOTES}
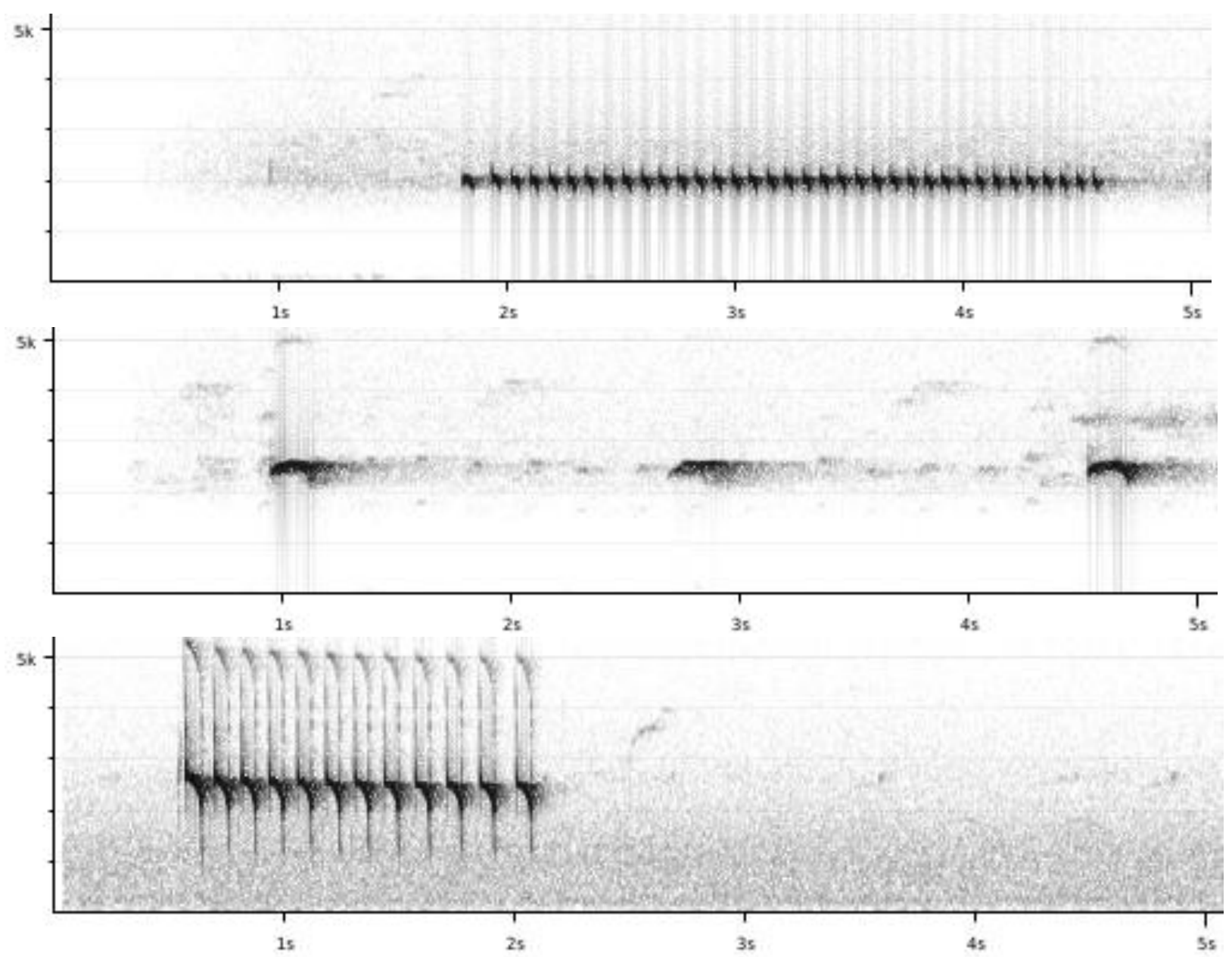

Figure 1: Typical song of northern birds (top) and southern birds (middle), and call of southern birds (bottom).

This note was finalized on 22nd June 2015, using sound recordings available on-line at that moment. We would like to thank in particular the sound recordists who placed their recordings for this species on XC: Nick Athanas, David Beadle, Peter Boesman, Ross Gallardy, David Geale, John Hornbuckle, Jon King, Niels Krabbe, Frank Lambert, Hans Matheve, Fabrice Schmitt, Andrew Spencer, Herman Van Oosten

\section{References}

Tobias, J.A., Seddon, N., Spottiswoode, C.N., Pilgrim, J.D., Fishpool, L.D.C. \& Collar, N.J. (2010). Quantitative criteria for species delimitation. Ibis 152(4): 724-746.

\section{Recommended citation}

Boesman, P. (2016). Notes on the vocalizations of Chestnut Antpitta (Grallaria blakei). HBW Alive Ornithological Note 250. In: Handbook of the Birds of the World Alive. Lynx Edicions, Barcelona. (retrieved from http://www.hbw.com/node/932249 on 4 October 2016). 